One of the promising methods for improving the uniformity of seed distribution in the soil is the control of the grain flow by guiding elements in the openers. This creates favorable conditions for the flight of seeds in the openers and when leaving them backwards, which equalizes the speed, in modulus, of seeds and the unit, improves the uniformity of their distribution in the soil.

The presence and parameters of the guiding elements of the openers was theoretically substantiated, which gave the development of the process of controlling the grain flow in the openers and at the exit from them by using the guiding elements.

Analytical expressions have been obtained to determine the characteristics of the movement of particles on various surfaces, which are recommended to be used for guides in the openers.

Experimental studies have shown that openers with guides reduce the coefficient of variation along the row by $20 . .45 \%$ and have it $88 . .98 \%$, and in depth $-24 . .27 \%$.

On the basis of experiments, it is recommended that $3 . . .4$ guides are recommended for front openers (arithmetic mean interval along the row $18.5 \ldots 23.5 \mathrm{~mm}$, coefficient of variation $88 . . .98 \%$ ).

The advantage of the experimental opener in the distribution of seeds by depth is due to the use of guide elements in combination with an improved soil shedding process. This eliminated the technological drawback - the formation of a sub-opener inclined surface (arithmetic mean interval $42 . .37 \mathrm{~mm}$, coefficient of variation $24 . .27 \%$ ).

For a double disc opener, an improved guide is recommended, the bottom edge of which protrudes $2 \mathrm{~cm}$ in front of the vertical diameter of the discs and is located at a distance of $9 \mathrm{~cm}$ from the reference plane. The arithmetic mean spacing along the row of this opener is $15 \mathrm{~mm}$, the coefficient of variation is $106 \%$

Keywords: improved seed drill opener, seed guide, seed management, uniformity of seed distribution
UDC 631.331; 631.53.04; 005.336.1

DOI: $10.15587 / 1729-4061.2021 .239304$

\title{
SUBSTANTIATION OF THE PRESENCE AND PARAMETERS OF SEED GUIDES IN THE OPENERS, WHICH INCREASE THE QUALITY OF SOWING AND YIELD
}

Alexander Nanka

$\mathrm{PhD}$, Associate Professor, Rector**

Ivan Morozov

Corresponding author

Doctor of Technical Sciences, Professor*

E-mail: ivanmorozov1937@gmail.com

VIadimir Morozov

$\mathrm{PhD}$

Department of Economics and Marketing**

Mykola Krekot

$\mathrm{PhD}$ *

Anatolii Poliakov

$\mathrm{PhD}$, Associate Professor

Department Machine Repair, Energy Operation and Labor Protection $* * * *$

Ivan Kiralhazi

Assistant***

Mykhailo Lohvynenko Senior Lecturer***

Viktor Rydiaiev

$\mathrm{PhD}$, Associate Professor

Department Machine Repair, Energy Operation and Labor Protection****

Sergey Dyakonov

$\mathrm{PhD}$, Associate Professor

Department of Technical Support of Agro-industrial Production Kharkiv National Agrarian University named after V. V. Dokuchaiev p/o «Dokuchaevske-2», Kharkiv dist., Kharkiv reg., Ukraine, 62483

Mykola Stashkiv

$\mathrm{PhD}$, Associate Professor Department of Transport Technologies and Mecanical Ternopil Ivan Puluj National Technical University Ruska str., 56, Ternopil, Ukraine, 46001

*Department of Agricultural Machinery**

**Kharkiv Petro Vasylenko National Technical University of Agriculture

Alchevskih str., 44, Kharkiv, Ukraine, 61002 $* * *$ Department Mechanization of Production Processes in the Agro-Industrial Complex****

$* * * *$ Luhansk National Agrarian University Slobozhanska str., 68, Starobilsk, Ukraine, 92703

Received date 25.06.2021 Accepted date 18.08.2021 Published date 31.08.2021
How to Cite: Nanka, A., Morozov, I., Morozov, V., Krekot, M., Poliakov, A., Kiralhazi, I., Lohvynenko, M., Ryndiaiev, V., Dyakonov, S., Stashkiv, M. (2021). Substantiation of the presence and parameters of seed guides in the openers, which increase the quality of sowing and yield. Eastern-European Journal of Enterprise Technologies, 4(1 (112)), 61-75. doi: https://doi.org/10.15587/1729-4061.2021.239304

\section{Introduction}

The openers are the main working elements of the seeders, which determine the quality of the sowing. Therefore, the problem of creating openers capable of high-quality sowing in various ways of seeds of different crops is important. It is known that grain seeders are equipped mainly with front and disc openers, which have known drawbacks and do not fully 
meet modern agricultural requirements. They do not eliminate the sloping sub-opener surface, due to which the seeds are sown unevenly. Openers of all types do not form, nor do they orient the grain flow, which reduces the quality of sowing.

The sowing quality is assessed by the uniformity of the distribution of seeds in the soil in accordance with the requirements and depends on the orderliness of the grain flow, which is formed by the sowing device and enters the openers through the seed pipes. According to [1], the bulk of the seeds (from $2 / 3$ to $4 / 5$ ) while moving in the seed tube is practically in free fall conditions.

Improving the uniformity of seed distribution in the soil is implemented by various methods. One relatively new and promising method is grain flow control with seed guides in openers.

Therefore, studies aimed at identifying the regularities of the characteristics of the movement of particles on various surfaces should be recognized as relevant. This will improve the control of the grain flow in and out of the openers to improve the uniformity of seed distribution in the soil.

\section{Literature review and problem statement}

The authors of [1] noted that the study of the technological process of the formation of the grain flow is relevant from the appearance of the first seeder to the present day. It is fairly noted that this is due to changes in climatic conditions, sowing technologies, agronomic requirements and design parameters of seeders. Further, it is noted that not enough attention is paid to the process of forming and moving grain from the sowing device to the furrow. This emphasizes the relevance of the chosen topic. But it should be noted that the article presents the material in the staging plan.

To improve the uniformity of the distribution of seeds in the soil with anchor openers, it is proposed to use the inner surface of the opener as a guiding element [2]. At the same time, the theoretical substantiation of the shape of the frontal surface of the opener interacting with the soil and the inner surface interacting with the seeds is interrelated and complicated. Therefore, the article does not contain specific recommendations for the shape parameters of these elements.

The work [3] presents an opener in the form of a cultivator paw with a two-plane seed spreader. The working body is of practical interest. The theoretical substantiation of the parameters of the working elements is not provided.

The work [4] provides an analysis of the openers of seeders of resource-saving technologies for sowing grain crops. It is noted that most of the energy during sowing is spent on the interaction of the seeding working bodies with the soil. But the article does not provide data on improving the parameters of working bodies that reduce energy performance. Emphasis is placed on performance and the organization of the sowing campaign.

The work [5] shows the design of a combined opener for sowing small-seeded oilseeds. Here the design of the opener is described in detail, details are given, their meaning and the quality of their operations. The information is of practical importance. For the described opener, it is advisable to improve the process of interaction of the opener with soil and seeds. However, there is no substantiation of the parameters interacting with soil and seeds.

The author of work [6] simulates the process of soil movement on the surface of the working bodies of tillage machines. Methods and mathematical apparatus are used that are of interest to science and can be useful for researchers to substantiate the parameters of the working bodies of tillage machines. But theoretical studies on the substantiation of the parameters of the working bodies interacting with the soil are not given.

In [7], an analysis of the functioning of openers for direct sowing of grain crops is made. The characteristic of the design and operating parameters of the working bodies is absent in this work. Therefore, it is difficult to imagine the validity of the technological process of the openers in question. Poor quality work of the opener openers is noted. This is due to insufficient consideration of real conditions in the theoretical substantiation of the shape and parameters of the surfaces of the working bodies that interact with the soil and seeds.

The authors of [8] created an opener equipped with a share and a compacting roller. The rationale for the parameters of the openers interacting with the seeds is not presented here. Therefore, the published information is of practical importance only.

In [9], the authors presented solutions for a combined opener for applying seeds and fertilizers with a soil layer between them. The technical solution is of interest and has only practical value.

In [10], a diagram of the interaction of the opener with the soil is presented. The need for a reasonable choice of the parameters of the openers interacting with the soil is noted, however, no specific recommendations have been made regarding such a choice.

The article [11] shows the theoretical substantiation of the parameters of the sowing section of a vegetable seeder. Recommendations are given for the movement of seeds and their orientation when flying out of the opener into the furrow, but no justification for the parameters of the guide is given.

In [12], the process of seed movement in a tubular guide is considered. Theoretical substantiations of the characteristics of the movement of seeds along the guide are given. But the seed guide is presented in the abstract without belonging to any opener.

The authors of the article [13] consider the problem of improving the quality of planting seeds on an unprepared agro background for sowing. In this work, a disc was introduced into the design, the task of which is to shift the crop residues to the sides, to cut the soil to a given sowing depth. A opener is installed after the disc, which introduces seeds into the soil. The article gives the percentage of improvement in the quality of seed placement, which is doubtful. Since the soil environment with crop residues is a multiphase environment and it is impossible to take into account not only tenths of a percent, but also the absolute value in percent. In this work, the guiding elements for seeds were not considered and is not of interest for our considered problem.

In the materials of the article [14], studies of soil conditions and traction forces are presented as dynamic factors affecting the technological process. Also shown are the studies of the opener with wings with parameters $\alpha$ and $\beta$. In the course of research, the angles $\alpha$ and $\beta$ were changed. In the conclusions, the author concludes that the angle $\beta$ significantly affects the technological process and the angle $\alpha$ has a negligible effect. In their conclusions, the authors give recommendations for the optimal values of the angles $\alpha$ and $\beta$. As it is possible to see in the article, the interaction of the working bodies with the soil was considered and did not affect the interaction with the seeds. In general, the article is of scientific interest, but not for our problem under consideration. 
The article [15] presents studies of three working bodies in a three-component soil (sand, silt and clay) at a depth of 25 and $50 \mathrm{~mm}$. With a density of $1184 \mathrm{~kg} / \mathrm{m}^{3}$ and moisture content of $25.8 \%$. In the conclusions, the authors assess the quality of the work of the openers in terms of their interaction with the soil. The article is of scientific interest from the point of view of the interaction of the openers with the soil. The interaction of the openers with the seeds was not considered and is not of interest for our work.

The article [16] presents the materials of the study of the combined opener, which has sharp and obtuse angles of entry into the soil. The characteristics and parameters of the interaction of this opener with the soil are described. The information provided does not include the interaction of the opener with the seed. The article is of scientific interest, but the authors do not refer to [17].

In the presented material [18], curved openers with front angles from 45 to 90 degrees were studied. The purpose of the research is to determine the quality of the interaction of working bodies with the soil. The best indicators of interaction with the soil were shown by the opener with a front angle of 90 degrees. Experimental studies were carried out at the modern level with the manufacture and study of physical models of openers. The article is of practical and scientific interest but to the problem the interaction of the opener with the seeds is irrelevant.

Based on the analysis of the sources [1-18], it can be concluded that there are unresolved issues related to improving the uniformity of seed distribution by guiding elements in the openers.

\section{The aim and objectives of research}

The aim of research is to improve the efficiency of the sowing technological process by improving the openers of seeders. This will improve the uniformity of seed distribution in the soil.

To achieve this aim, it is necessary to solve the following objectives:

- theoretically determine the parameters of the movement of particles along guiding surfaces of various shapes and conditions in order to match the movement of particles with the characteristics of the movement of the sowing unit to improve the quality of sowing (distribution of seeds in the soil, which will improve gatherings, plant growth and yield);

- to make physical models of the guide, install them on experimental openers and conduct experiments to determine the quality of sowing.

\section{Materials and methods of research}

The experimental research program consisted of a series of laboratory and field studies of grain seeders with experimental openers.

\section{1. Laboratory research}

Laboratory experiments investigated the influence of the presence of guide seeds, their quantity and parameters on the uniformity of seed distribution.

In laboratory studies, the uniformity of the stroke in depth was determined, serial and experimental openers were installed on special leashes (Fig. 1), on which the RV16LN (PH) potentiometers were fixed according to the scheme (Fig. 2). The potentiometer rod through a lever and a rod was con- nected to the upper transverse bar of the trolley. The ends of the electric winding of the potentiometer were connected with flexible wires to the socket, which was fixed on the trolley. The ends of the winding were connected with a cable to the galvanometer of the N-115 oscilloscope (the time stamp error was $\pm 1.5 \%$, the limitation of the oscillogram length was from $0.2 \mathrm{~m}$ to $4 \mathrm{~m}$ ).

Oscillograms were processed with a POBD-12 device manufactured at VISKHOM. This device has been discontinued and at present the oscillograms are processed on modern computers using the FastView 4.0 software product.

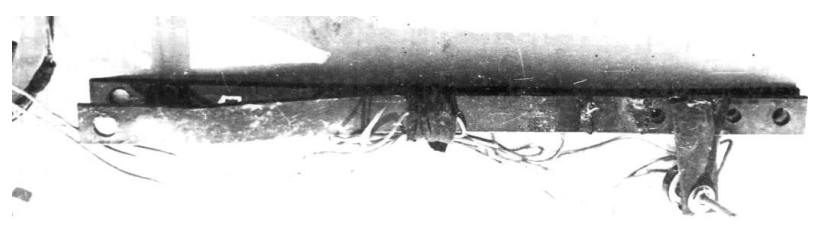

Fig. 1. Opener driver with potentiometer

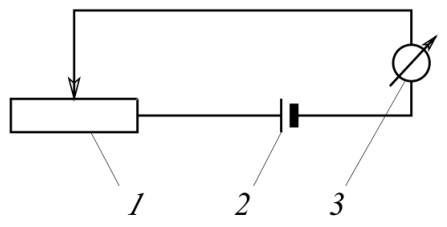

Fig. 2. Electrical diagram of the leash device with a potentiometer: 1 - potentiometer; 2 - power supply; 3 - measuring device (oscilloscope)

When carrying out experiments in laboratory conditions, they were sown on adhesive tape and the intervals between adjacent grains along the row were measured.

Statistical data processing in determining the agrotechnical performance of the seeder is as follows. The main indicators of processing statistical series are as follows: $\bar{x}$ - arithmetic mean interval between seeds in the soil along the row or in depth, $\sigma$ - standard deviation, $V$ - coefficient of variation, $m$ - mean error of the arithmetic mean, and $P$ - experimental accuracy in percent. Comparing these indicators, let's draw conclusions about the quality of sowing by the working bodies. Statistical processing was carried out according to the sources [19-22].

\section{2. Field research}

Field research involved testing theoretical assessments and confirming the results obtained in laboratory experiments.

The field research program was supposed to test the performance of experimental openers in real field conditions.

When choosing a research methodology, the main requirement was to ensure that reliable results are obtained.

The methods of differential and integral calculus of the set tasks were used.

Theoretical problems of particle motion along an inclined plane with and without the resistance of the medium; movement of a particle along an arc of a circle and a cycloid were solved.

In addition to the listed methods, the research was guided by the requirements of GOST (DSTU ISO 7256-1:2005 Sowing equipment. Test methods).

Methods were used: computational and constructive, experimental, physical modeling, operational to assess the quality of machines.

Field experiments were carried out in two stages.

At the first stage, a qualitative assessment of the work of the experimental openers was carried out in comparison with 
serial working bodies in real production conditions, which took place at the time of the research. The permeability of seeds in the channels of the openers was investigated. The sowing quality criteria were the uniformity of seed distribution in the soil along the line and along the depth, depending on the speed of the seeder.

The studies of the second stage were carried out in such farms of the Kharkiv region: «May 1» KNTUA; fattening farm (Pechenihy) of Chuhuiv district; KSP «Borivske» of the Shevchenko district. Experimental conditions: soil washed away podzolic chernozems. The soil after autumn plowing in spring was cultivated to a depth of 10-12 cm with simultaneous harrowing with tooth harrows. Soil density $1000 \mathrm{~kg} / \mathrm{m}^{3} \pm 5 \%$. Soil moisture in the range of $16-20 \%$.

The study of this stage provided for a qualitative assessment of the work of the experimental openers at different speeds, within $11-12 \mathrm{~km} / \mathrm{h}$, in various soil and climatic conditions.

When carrying out the experiment in the field, after the emergence of seedlings, the distances along the line between neighboring plants were measured. The depth of seed placement was measured according to the etiolated part of the plants.

The obtained statistical series were processed by the methods of variation statistics and the parameters were obtained: the arithmetic mean interval, standard deviation, coefficient of variation, mean error of the arithmetic mean interval, the accuracy of the experiment and entered them into tables. Compared the absolute values of these parameters and made conclusions. Based on these data, let's establish the final required sample size and, having received the initial values, let's determine the average value and its error (for soil indicators) or the fraction error (for seed germination).

Sample size was calculated by the value of the indicator variation depending on the required determination accuracy.

This device was used to assess the quality of the experimental openers in laboratory and field conditions at different speeds in comparison with serial working bodies.

\section{Research results of openers and their elements}

5. 1. Theoretical determination of the parameters of particle motion along guiding surfaces

For the technical solution of this problem, guide elements for seeds are introduced into the design of the opener (Fig. 3).

For this, the motion of a spherical particle along an inclined plane was considered. This assumption is made to simplify the solution of the problem.
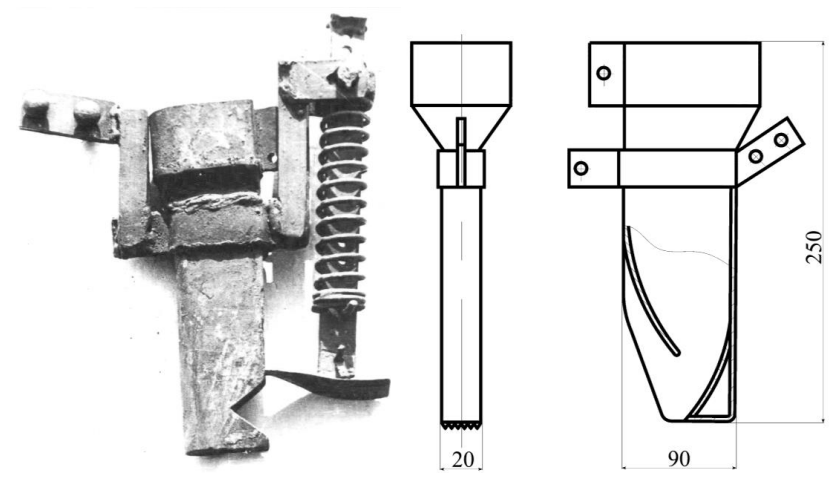

Fig. 3. General view of the experimental opener with a right angle of entry into the soil with a guide and a seed reflector
Let a spherical particle of radius a move along an inclined plane without friction and sliding. The angle between the horizon and the inclined plane will be denoted by $\alpha$. In Fig. 4 shows a section of a given inclined plane by a vertical plane $X O Y$ (further, the problem was solved in a rectangular coordinate system on a plane), passing through the line of contact of the particle with the plane in question. Equation of this line in the selected coordinate system:

$$
y=k x
$$

where $k=\operatorname{tg} \alpha-$ slope coefficient.

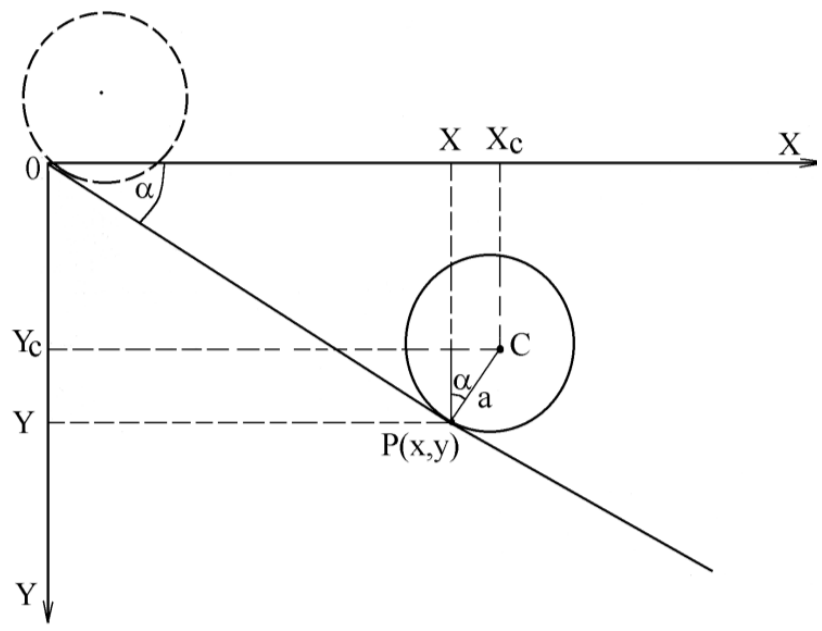

Fig. 4. Scheme of particle motion along an inclined plane

Let's write down the expression for the total mechanical energy of the particle at the moment when it comes into contact with the inclined plane at the point $P(x, y)$.

Particle kinetic energy:

$$
W_{n}=\frac{m v^{2}}{2}+\frac{J \omega^{2}}{2}
$$

where $m$ - mass of the particle $(\mathrm{kg}), v$ - its linear speed $(\mathrm{m} / \mathrm{s})$, i. e., the speed of the center of the ball $C$; $\omega$ - angular speed of a particle (rad/s); $J$ - moment of inertia of the particle about the axis passing through point $C$.

Taking into account that $\omega=v / \alpha, J=m \rho^{2}$, where $\rho$ - radius of gyration of the particle $(\mathrm{m})$, obtained:

$$
W_{n}=\frac{m v^{2}}{2}\left(\frac{a^{2}+\rho^{2}}{a^{2}}\right)
$$

Because:

$$
v^{2}=v_{x}^{2}+v_{y}^{2}=\left(\frac{d x}{d t}\right)^{2}+\left(\frac{d y}{d t}\right)^{2} \equiv \dot{x}^{2}+\dot{y}^{2},
$$

then for this case the square of the linear speed is determined through its horizontal component and the slope:

$$
v^{2}=\dot{x}^{2}\left(1+k^{2}\right)
$$

Substituting (9) into (8), let's obtain:

$$
W_{n}=\frac{\left(\rho^{2}+a^{2}\right)\left(1+k^{2}\right)}{2 a^{2}} m \dot{x}^{2} .
$$


The potential energy of a particle is determined by the expression:

$$
W_{n}=-m g y_{c}+C_{1}
$$

where $y_{c}-$ coordinate of the center of the particle $(m)$; $g$ - acceleration of gravity $\left(\mathrm{m} / \mathrm{s}^{2}\right) ; C_{1}-$ constant depending on the choice of the initial configuration of the «particleplane» system.

An initial configuration was chosen such that $y_{c}=0$, $W_{n}=0$. In this case, $C_{1}=0$ and, taking into account that $y_{c}=y(x)-a \cos \alpha$, the expression for the potential energy takes the form:

$$
W_{n}=-m g(y(x)-a \cos \alpha)
$$

Since $\cos \alpha=\left(1+k^{2}\right)-1 / 2$, the expression for the potential energy can be written in the form:

$$
W_{n}=-m g k x+\frac{m g a}{\sqrt{1+k^{2}}} .
$$

Let's note that for the selected initial configuration of the «particle-plane» system, the potential energy of a particle with coordinates $x=0, y=0$, as seen from (13), is nonzero.

Taking into account formulas (10) and (13), the following expression was obtained for the total mechanical energy of a particle:

$$
W=\frac{\left(\rho^{2}+a^{2}\right)\left(1+k^{2}\right)}{2 a^{2}} m \dot{x}^{2}-m g k x+\frac{m g a}{\sqrt{1+k^{2}}} .
$$

Since the system under consideration is conservative under the indicated conditions, its total mechanical energy is conserved,

$$
\frac{\left(\rho^{2}+a^{2}\right)\left(1+k^{2}\right) m \dot{x}^{2}}{2 a^{2}}-m g k x+\frac{m g a}{\sqrt{1+k^{2}}}=\text { const. }
$$

Based on condition (15), the particle motion equation is obtained. For this, it is differentiated (15) by time:

$$
\begin{aligned}
& \frac{\left(\rho^{2}+a^{2}\right)\left(1+k^{2}\right) m}{a^{2}} \ddot{x} \ddot{x}-m g k \ddot{x}=0, \\
& m \dot{x}\left[\frac{\left(\rho^{2}+a^{2}\right)\left(1+k^{2}\right)}{a^{2}} \ddot{x}-g k\right]=0 .
\end{aligned}
$$

From this, the following equation of motion of a particle in differential form was obtained:

$$
\frac{\left(\rho^{2}+a^{2}\right)\left(1+k^{2}\right)}{a^{2}} \ddot{x}-g k=0 .
$$

$\dot{x}=0$ corresponds to the trivial case.

Therefore, the horizontal component of the particle acceleration $W_{x}$ :

$$
W_{x} \equiv \ddot{x}=\frac{a^{2} g k}{\left(\rho^{2}+a^{2}\right)\left(1+k^{2}\right)} .
$$

By integrating (16), the horizontal component of the particle speed is determined:

$$
\dot{x}=\frac{a^{2} g k}{\left(\rho^{2}+a^{2}\right)\left(1+k^{2}\right)} t+C_{2} .
$$

The constant $C_{2}$ is determined from the initial conditions: at $t=0, \dot{x}_{0}=C_{2}$, i. e., $C_{2}$ is equal to the horizontal component of the initial speed $V_{o x}$; therefore, the horizontal component of the particle speed:

$$
V_{x}=\dot{x}(t)=\frac{a^{2} g k t}{\left(\rho^{2}+a^{2}\right)\left(1+k^{2}\right)}+V_{o x},
$$

similarly,

$$
V_{y}=\dot{y}(t)=\frac{a^{2} g k^{2} t}{\left(\rho^{2}+a^{2}\right)\left(1+k^{2}\right)}+V_{o y},
$$

where $V_{o y}$ - vertical component of the initial speed. By integrating (19), (20), the equations of motion are found:

$$
\begin{aligned}
& x(t)=\frac{a^{2} g k t^{2}}{2\left(\rho^{2}+a^{2}\right)\left(1+k^{2}\right)}+V_{o x} t+C_{3}, \\
& y(t)=\frac{a^{2} g k^{2} t^{2}}{2\left(\rho^{2}+a^{2}\right)\left(1+k^{2}\right)} V_{o y} t+C_{4} .
\end{aligned}
$$

From the condition $x=y=0$ at $t=0$ it follows that the constants $C_{3}=C_{4}=0$, and the equations of motion take the form:

$$
\begin{aligned}
& x(t)=\frac{a^{2} g k t^{2}}{2\left(\rho^{2}+a^{2}\right)\left(1+k^{2}\right)}+V_{o x} t, \\
& y(t)=\frac{a^{2} g k^{2} t^{2}}{2\left(\rho^{2}+a^{2}\right)\left(1+k^{2}\right)}+V_{o y} t .
\end{aligned}
$$

The last expressions make it possible to choose the value of the parameter $k$ depending on the required final required values of the speed components and the given initial conditions. Equations (23), (24) make it possible to determine the coordinates of the point at which the particle has these speeds.

With a uniform density in a spherical particle, its radius of gyration $\rho=\sqrt{2 / 5} a$, therefore $\left(\rho^{2}+a^{2}\right) / a^{2}=7 / 5$, from which it follows that in this case $x(t)$ and $y(t)$ do not depend on the radius of the particle:

$$
\begin{aligned}
& x(t)=\frac{5 g k t^{2}}{14\left(1+k^{2}\right)}+V_{o x} t, \\
& y(t)=\frac{5 g k^{2} t^{2}}{14\left(1+k^{2}\right)}+V_{o y} t .
\end{aligned}
$$

Consequently, the expressions for the horizontal $V_{x}$ and vertical $V_{y}$ components of the speed take the form:

$$
\begin{aligned}
& \dot{x}(t)=\frac{5 g k t}{7\left(1+k^{2}\right)}+V_{o x}, \\
& \dot{y}(t)=\frac{5 g k^{2} t}{7\left(1+k^{2}\right)}+V_{o y} .
\end{aligned}
$$

If the «particle-plane» system moves in the direction of negative values of $x$ at a known speed $V_{x}$, equations (27), (28) make it possible to determine the conditions under which this speed will be equal to zero relative to the stationary system.

This problem can be solved as a special case of the problem of the motion of a ball along an arbitrary curve, [23].

The found equation of motion of the ball in quadrature form has the form: 


$$
\frac{a t}{\sqrt{a^{2}+\rho^{2}}}=\int_{o}^{x} \frac{\sqrt{1+y^{\prime 2}(x)}+\frac{a y^{\prime \prime}(x)}{1+y^{\prime 2}(x)}}{\frac{2 W_{o}}{m}+2 g y(x)-\frac{2 a g}{\sqrt{1+y^{\prime 2}(x)^{1 / 2}}}} \mathrm{~d} x,
$$

here $y^{\prime}(x)=d y / d x ; y^{\prime \prime}(x)=d^{2} y / d t^{2}$.

For the case $y(x)=k x$ there is $y^{\prime}(x)=k ; y^{\prime \prime}(x)=0$ and after substituting these values into (29), let's obtain:

$$
\begin{aligned}
& \frac{a t}{\sqrt{\rho^{2}+a^{2}}}=\int_{o}^{x} \frac{\sqrt{1+k^{2}} \mathrm{~d} x}{\sqrt{\frac{2 W_{o}}{m}+2 g k x-\frac{2 a g}{\sqrt{1+k^{2}}}}}= \\
& =\frac{1}{g k} \sqrt{\frac{2 W_{o}}{m}-\frac{2 a g}{\sqrt{1+k^{2}}}+\left.2 g k x\right|_{0} ^{x}}= \\
& =\frac{1}{g k}\left[\sqrt{\frac{2 W_{o}}{m}-\frac{2 a g}{\sqrt{1+k^{2}}}+2 g k x}-\sqrt{\frac{2 W_{o}}{m}-\frac{2 a g}{\sqrt{1+k^{2}}}}\right] .
\end{aligned}
$$

Solving equation (30) for $x$, found:

$$
x=\frac{a^{2} g k t^{2}}{2\left(a^{2}+\rho^{2}\right)\left(1+k^{2}\right)}+\frac{a \sqrt{\frac{2 W_{o}}{m}-\frac{2 a g}{\sqrt{1+k^{2}}}}}{\sqrt{a^{2}+\rho^{2}} \sqrt{1+k^{2}}} t .
$$

Comparing (31) and (23), let's note that the coefficients at $t^{2}$, which have the meaning of the horizontal component of acceleration, coincide, and the coefficient at $t$ in (31) equal to the horizontal component of the initial speed $V_{o x}$ is taken to be zero. Indeed, as follows from [23], for $x=y=0$, $W_{o}=m g a / \sqrt{1+k^{2}}$.

$$
\sqrt{\frac{2 W_{o}}{m}-\frac{2 a g}{\sqrt{1+k^{2}}}}=\sqrt{\frac{2 m g a}{m \sqrt{1+k^{2}}}-\frac{2 a g}{\sqrt{1+k^{2}}}}=0,
$$

hence $V_{o x}=0$.

The problem is considered under the initial conditions, when the particle arrives at the point $(0,0)$ with arbitrary but adjustable values of the speed components $V_{o x}$ and $V_{o y}$.

As a result of solving this problem, equations are obtained that allow one to determine such characteristics of the particle's motion as its coordinates and speed components. These equations can be used to determine the parameters of the guiding elements of the openers for various seeds, differing in density, sown at different operating modes of the seeding units. In the course of experimental studies, the speed of the seeding units varied depending on the real conditions (11-12 km/h).

\section{1. 2. Movement of a particle along an arc of a circle}

The rolling of a ball of radius a along an arc of a circle of radius $R$ under the action of gravity without friction and sliding is considered (Fig. 5).

The center of the circle is point $C^{\prime}$, the center of the ball is point $C$. At the initial moment, the ball is in contact with point $O^{\prime}$ with the arc of the circle at point $O$, which is chosen as the origin. The $y$-axis coincides with the direction of gravity, the $x$-axis is perpendicular to this direction.

$\varphi$ - angle between the $x$-axis and the normal to the circular arc $P C^{\prime}=R$ at the point $P$ of contact of the ball at a certain moment of time $t$.

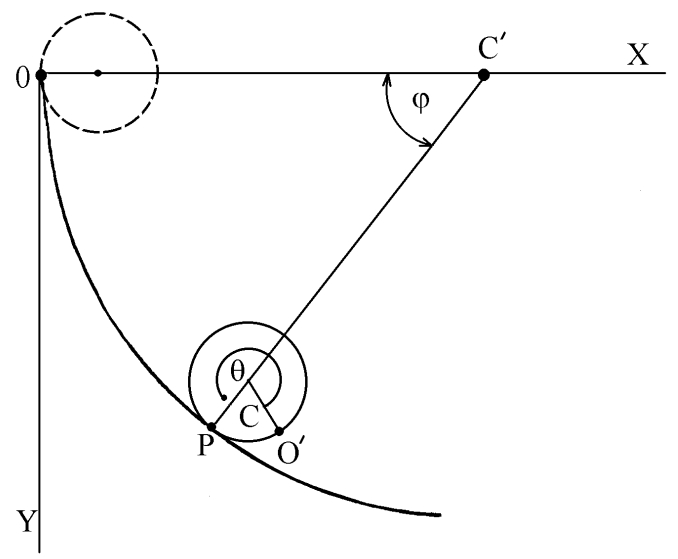

Fig. 5. Scheme of motion of a particle along an arc of a circle

The length of the arc $S=O P=R \varphi=\theta a$, where $\theta-$ angle between the radii of the ball $C O^{\prime}$ and $C P$, drawn to the points of contact $O$ and $P$ at the initial and considered moment of time, respectively.

The equation of a circle centered at point $C^{\prime}$ in parametric form has the form:

$$
\begin{aligned}
& x=R(1-\cos \varphi), \\
& y=R \sin \varphi .
\end{aligned}
$$

Movement along a quarter of a circular arc was considered, so $0 \leq \varphi \leq \pi / 2$.

Angle of rotation $\Psi$ of the rolling ball radius relative to its initial direction $C^{\prime} O$ :

$$
\Psi=\theta-\varphi=\frac{s}{a}-\varphi
$$

Circular arc element:

$$
d s=R d \varphi
$$

Angular speed of a rolling ball:

$$
\omega=\frac{d \Psi}{d t}=\frac{R-a}{a} \cdot \frac{d \varphi}{d t}=\frac{R-a}{a} \dot{\varphi} .
$$

Linear speed of the center of the ball:

$$
v_{c}=\sqrt{\left(\frac{d x_{c}}{d t}\right)^{2}+\left(\frac{d y_{c}}{d t}\right)^{2}},
$$

where $x_{c}$ and $y_{c}$ - coordinates of the center of the ball:

$$
\begin{aligned}
& x_{c}=x+a \cos \varphi, \\
& y_{c}=y-a \sin \varphi .
\end{aligned}
$$

Taking into account (32) and (33):

$$
\begin{aligned}
& x_{c}=R-(R-a) \cos \varphi, \\
& y_{c}=(R-a) \sin \varphi .
\end{aligned}
$$

Differentiating (40) and (41) with respect to time, the horizontal and vertical components of the speed of the center of the ball were found: 
$v_{x c}=\dot{x}_{c}=(R-a) \sin \varphi \cdot \dot{\varphi}$,

$v_{y c}=\dot{y}_{c}=(R-a) \cos \varphi \cdot \dot{\varphi}$.

Substitution of (42) and (43) in (37), let's obtain:

$v_{n}=(R-a) \dot{\varphi}$

Kinetic energy of a rolling ball:

$W_{n}=\frac{m v_{c}^{2}}{2}+\frac{I \omega^{2}}{2}$

where, $m$ - mass of the ball, $I$ - moment of inertia of the ball relative to the axis passing through its center,

$$
I=m \rho^{2}
$$

where $\rho$ - radius of gyration of the ball.

From expressions (36), (44), (45) it is found:

$$
W_{n}=\frac{m}{2}(R-a)^{2} \frac{a^{2}+\rho^{2}}{a^{2}} \varphi^{2}
$$

The potential energy of the sphere relative to the horizontal axis $O X$, taking into account (41),

$$
W_{n}=-m g y_{c}=-m g(R-a) \sin \varphi .
$$

By adding (46) and (47), the total mechanical energy of the ball is obtained:

$$
W=\frac{m(R-a)^{2}\left(a^{2}+\rho^{2}\right)}{2 a^{2}} \dot{\varphi}^{2}-m g(R-a) \sin \varphi,
$$

where it is defined:

$$
\dot{\varphi}=\frac{a \sqrt{2}}{(R-a) \sqrt{a^{2}+\rho^{2}}} \sqrt{\frac{W}{m}+g(R-a) \sin \varphi} .
$$

By integrating the differential equation (49), it is found:

$$
\frac{a \sqrt{2} t}{(R-a) \sqrt{a^{2}+\rho^{2}}}=\int_{o}^{\varphi} \frac{\mathrm{d} \varphi}{\sqrt{\frac{W}{m}+g(R-a) \sin \varphi}}
$$

According to the law of conservation of energy, $W$ is a constant value independent of $\varphi$.

The right-hand side in (50) is represented in terms of an elliptic integral of the first kind, but is not expressed in elementary functions.
Numerical integration can be applied to determine the dependence $\varphi(t)$.

However, formulas (42), (43), (49) make it possible to find the speed of the center of the ball and its components for any value $\varphi$, i. e., at any point of the trajectory of motion:

$$
\begin{aligned}
& v_{x c}=\frac{a \sqrt{2}}{\sqrt{a^{2}+\rho^{2}}} \sin \varphi \sqrt{\frac{W}{m}+g(R-a) \sin \varphi}, \\
& v_{y c}=\frac{a \sqrt{2}}{\sqrt{a^{2}+\rho^{2}}} \cos \varphi \sqrt{\frac{W}{m}+g(R-a) \sin \varphi}, \\
& v_{c}=\frac{a \sqrt{2}}{\sqrt{a^{2}+\rho^{2}}} \sqrt{\frac{W}{m}+g(R-a) \sin \varphi .}
\end{aligned}
$$

If the density distribution of matter in the ball is constant, then $m \rho^{2}=2 / 5 m a^{2}$ and the numerical coefficient in formulas (51)-(53) is equal $\sqrt{10 / 7}$.

If the total energy of the ball is zero, then the speed formulas for a homogeneous ball take the form:

$$
\begin{aligned}
& v_{x c}=\sqrt{\frac{10}{7}(R-a) \sin ^{3} \varphi \cdot g,} \\
& v_{y c}=\sqrt{\frac{10}{7}(R-a) \sin \phi \cos ^{2} \varphi \cdot g}, \\
& v_{c}=\sqrt{\frac{10}{7} g(R-a) \sin \varphi .}
\end{aligned}
$$

At the end point of the quarter circle, for $\varphi=p / 2$ :

$$
\begin{aligned}
& v_{x c}=v_{c}=\sqrt{\frac{10}{7}(R-a) g}, \\
& v_{y c}=0 .
\end{aligned}
$$

Under the condition $R>a$ :

$$
v_{c}=v_{x c}=\sqrt{\frac{10}{7} R g} .
$$

By appropriately choosing the $R$ value, the required speed $v_{x c}$ can be obtained, which can be used to calculate the parameters of the guide elements for the seeds in the openers.

In Fig. 6, 7, graphs are plotted according to equations (54) and (55), which show the dependences of the speed components of the particle on the radius of curvature of the guiding curve and the size of the particle.

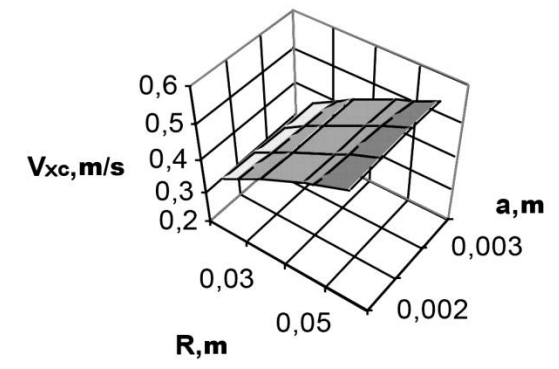

$a$

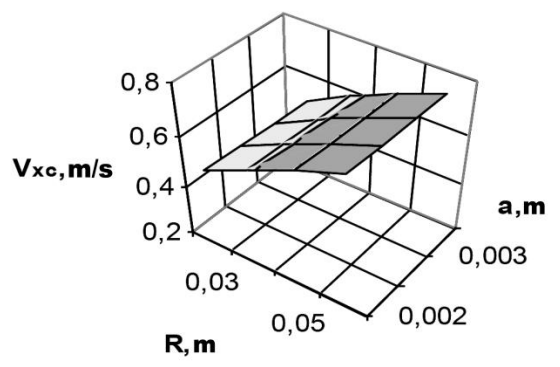

$b$

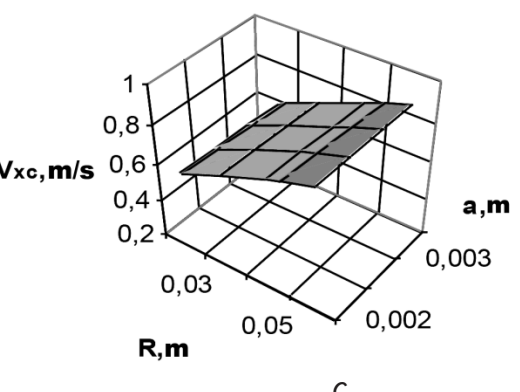

Fig. 6 . The surface of the response $V_{x c}$ from the radius of the circle, the diameter of the particles and the angle between the radius of the circle and the horizontal: $a-\varphi=45^{\circ} ; b-\varphi=60^{\circ} ; c-\varphi=75^{\circ}$ 


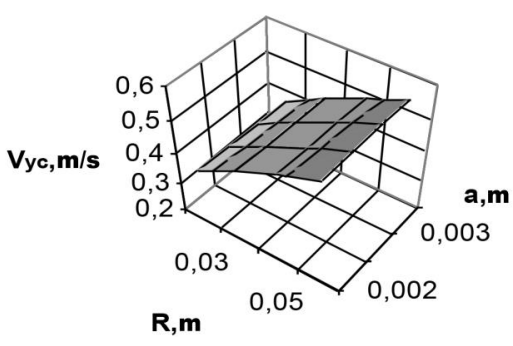

a
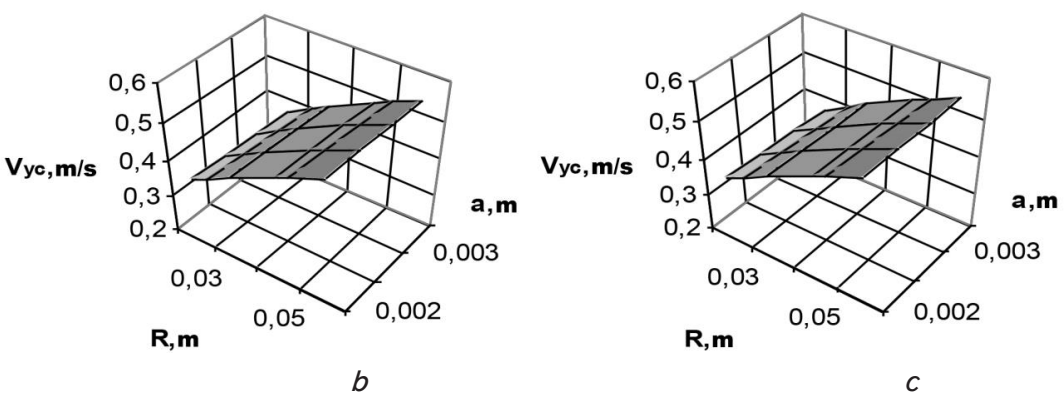

Fig. 7. The surface of the response $V_{y c}$ from the radius of the circle, the diameter of the particles and the angle between the radius of the circle and the horizontal: $a-\varphi=45^{\circ} ; b-\varphi=60^{\circ} ; c-\varphi=75^{\circ}$

Analysis of the graphs (Fig. 6, 7) shows that the particle speed is most significantly affected by the radius of the guiding curve and the particle size. This allows to state that the surface in the form of an arc of a circle can be used as a guide for most cereal seeds (wheat variety Myronivska 808). For other seeds, modes of robots of sowing units and their functioning, it is necessary to search, investigate and substantiate the parameters that affect the quality of sowing and yield.

5. 1. 3. Movement of a particle along the arc of a cycloid A spherical particle of radius a, mass m moves along the arc of a cycloid without friction and sliding. Let's choose a coordinate system in such a way that the $x$-axis lies in the horizontal plane, and the $y$-axis lies in the vertical plane.

Cycloid equation:

$$
\begin{aligned}
& x=R(\varphi-\sin \varphi), \\
& y=R(1-\cos \varphi),
\end{aligned}
$$

where, $R$ - radius of the circle, the point of which describes the cycloid when the circle rolls along the straight line $O X$ (in Fig. 8 - from below), $O$ - origin of coordinates, $\varphi$ - angle of rotation of the radius of the circle. At the moment $t=0$, the particle touches the cycloid at the origin of coordinates $\left(x_{0}=y_{0}\right)$, the trajectory of motion is limited by half of the cycloid arc corresponding to the range of variation of the parameter $\varphi$ from 0 to $\pi$.

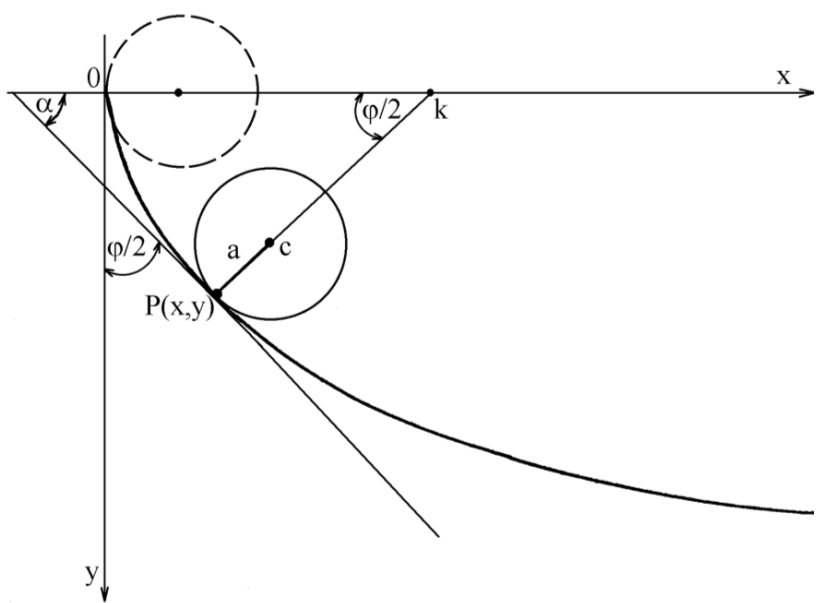

Fig. 8. Scheme of movement of a particle along the arc of a cycloid

In the general case, the equation of motion of a ball along an arbitrary curve in quadrature form has the form (29):

$$
\frac{a t}{\sqrt{a^{2}+\rho^{2}}}=\int_{0}^{x} \frac{\left(\sqrt{1+y^{\prime 2}(x)}+\frac{a y^{\prime \prime}(x)}{1+y^{\prime 2}(x)}\right) \mathrm{d} x}{\sqrt{\frac{2 W_{o}}{m}+2 g y(x)-\frac{2 a g}{\sqrt{1+y^{\prime 2}(x)}}}},
$$

where, $y^{\prime}=d y / d x, y^{\prime \prime}=d^{2} y / d x^{2} ; W_{o}$ - total energy of the ball; $\rho$ - radius of gyration of the ball; $g$ - acceleration of gravity.

The above result was used to solve this problem. To do this, it is necessary to find $y^{\prime}(x), y^{\prime \prime}(x)$ and perform the integration.

Based on equations (60), (61), let's find:

$$
\frac{d y}{d \varphi}=R \sin \varphi ; \frac{d x}{d \varphi}=R(1-\cos \varphi),
$$

where

$$
y^{\prime}(x)=\frac{d y}{d x}=\operatorname{ctg} \frac{\varphi}{2}=\operatorname{tg} \alpha,
$$

where $\alpha$ - angle between the tangent to the cycloid and the $x$-axis:

$$
\begin{aligned}
& y^{\prime \prime}(x)=\frac{d^{2} y}{d x^{2}}=\frac{d}{d x}\left(\frac{d y}{d x}\right)=\frac{d}{d \phi}\left(\frac{d y}{d x}\right) \frac{d \varphi}{d x}= \\
& =-\frac{1}{4 R \sin ^{4} \frac{\varphi}{2}} .
\end{aligned}
$$

The following expressions are defined:

$$
\begin{aligned}
& 1+y^{\prime 2}(x)=1+\operatorname{ctg}^{2} \frac{\varphi}{2}=\frac{1}{\sin ^{2} \frac{\varphi}{2}}, \\
& \sqrt{1+y^{\prime 2}(x)}=\frac{1}{\sin \frac{\varphi}{2}} \\
& \frac{y^{\prime \prime}(x)}{1+y^{\prime 2}(x)}=-\frac{1}{4 R \sin ^{2} \frac{\varphi}{2}} \\
& y=2 R \sin ^{2} \frac{\varphi}{2} \\
& d x=2 R \sin ^{2} \frac{\varphi}{2} d \varphi
\end{aligned}
$$

Substituting (66)-(69) into the integrand of formula (62), let's found: 


$$
\begin{aligned}
& \frac{a t}{\sqrt{a^{2}+\rho^{2}}}=\int_{0}^{\varphi} \frac{\left(\frac{1}{\sin \frac{\varphi}{2}}-\frac{a}{4 R \sin ^{2} \frac{\varphi}{2}}\right) 2 R \sin ^{2} \frac{\varphi}{2} \mathrm{~d} \varphi}{\sqrt{\frac{2 W_{0}}{m}+4 g R \sin ^{2} \frac{\varphi}{2}-2 a g \sin \frac{\varphi}{2}}}= \\
& =\frac{R}{\sqrt{g R}} \int_{0}^{\varphi} \frac{\left(\sin \frac{\varphi}{2}-\frac{a}{4 R}\right) \mathrm{d} \varphi}{\left(\sin \frac{\varphi}{2}-\frac{a}{4 R}\right)^{2}+\frac{W_{0}}{2 m g R}-\frac{a^{2}}{16 R^{2}}} .
\end{aligned}
$$

The lower limit of integration in (70) is determined from equality (60).

Replacing $\sin \varphi / 2-a / 4 R=z$ the integral in (70) is reduced to the integral:

$$
I=2 \int_{-\frac{a}{4 R}}^{\sin \frac{\varphi}{2}-\frac{a}{4 R}} \frac{z d z}{\sqrt{\left(z^{2}+\frac{W_{0}}{2 m g R}-\frac{a^{2}}{16 R^{2}}\right)\left[1-\left(z+\frac{a}{4 R}\right)^{2}\right]}} .
$$

Let's suppose that the radius of the ball is much less than the radius of the circle, $a<R$, and put $W_{0}=0$, i. e., in the initial position, at $x=0$ and $y=0$, the particle is at rest. Under these conditions, from (70) let's easily find:

$$
\frac{a t}{\sqrt{a^{2}+\rho^{2}}}=\sqrt{\frac{R}{g}} \int_{0}^{\varphi} \mathrm{d} \varphi=\sqrt{\frac{R}{g}} \varphi
$$

whence follows:

$$
\varphi=\sqrt{\frac{a^{2}}{a^{2}+\rho^{2}} \cdot \frac{g}{R}} t
$$

With a uniform distribution of mass in the ball:

$$
\rho^{2}=\frac{2}{5} a^{2} \sqrt{\frac{a^{2}}{a^{2}+\rho^{2}}}=\sqrt{\frac{5}{7}}
$$

In this case, it is obvious:

$$
\varphi=\sqrt{\frac{5 g}{7 R}} t .
$$

Substituting (73) into (60), (61), let's obtain the equation of motion of a spherical particle along the arc of a cycloid:

$$
\begin{aligned}
& x=R\left(\sqrt{\frac{5 g}{7 R}} t-\sin \sqrt{\frac{5 g}{7 R}} t\right), \\
& y=R\left(1-\cos \sqrt{\frac{5 g}{7 R}} t\right) .
\end{aligned}
$$

Let's determine the horizontal and vertical components of the speed:

$$
\begin{aligned}
& \dot{x}=v_{x}=\sqrt{\frac{5}{7} g R\left(1-\cos \sqrt{\frac{5 g}{7 R}} t\right)} \\
& \dot{y}=v_{y}=\sqrt{\frac{5}{7} g R} \sin \sqrt{\frac{5 g}{7 R}} t .
\end{aligned}
$$

Full speed:

$$
v=\sqrt{\dot{x}^{2}+\dot{y}^{2}}=2 \sqrt{\frac{5}{7} g R} \sin \sqrt{\frac{5}{28} \frac{g}{R}} t .
$$

Acceleration components:

$$
\begin{aligned}
& \ddot{x}=\omega_{x}=\frac{5}{7} g \sin \sqrt{\frac{5 g}{7 R}} t, \\
& \ddot{y}=\omega_{y}=\frac{5}{7} g \cos \sqrt{\frac{5 g}{7 R}} t .
\end{aligned}
$$

Full acceleration:

$$
\omega=\sqrt{\ddot{x}^{2}+\ddot{y}^{2}}=\frac{5}{7} g \text {. }
$$

The dependence of the speed components on the angle $\varphi$ can be determined without resorting to the assumptions $a<R$ and $W_{0}=0$. According to expressions (76) and (77), graphs were built (Fig. 9,10), which allow to select the required component of the particle speed, taking into account the parameters of the opener and the operating mode of the seeder.

For this, the derivative was determined using equation (70):

$$
\frac{a}{\sqrt{a^{2}+\rho^{2}}} \cdot \frac{d t}{d \varphi}=\sqrt{\frac{R}{g}} \cdot \frac{\sin \frac{\varphi}{2}-\frac{a}{4 R}}{\sqrt{\left(\sin \frac{\varphi}{2}-\frac{a}{4 R}\right)^{2}+\frac{W_{0}}{2 m g R}-\frac{a^{2}}{16 R^{2}}}},
$$

where it came from:

$$
\dot{\varphi}=\frac{d \varphi}{d t}=\sqrt{\frac{g a^{2}}{R\left(a^{2}+\rho^{2}\right)}} \cdot \frac{\sqrt{\left(\sin \frac{\varphi}{2}-\frac{a}{4 R}\right)^{2}+\frac{W_{0}}{2 m g R}-\frac{a^{2}}{16 R^{2}}}}{\sin \frac{\varphi}{2}-\frac{a}{4 R}} \text {. }
$$

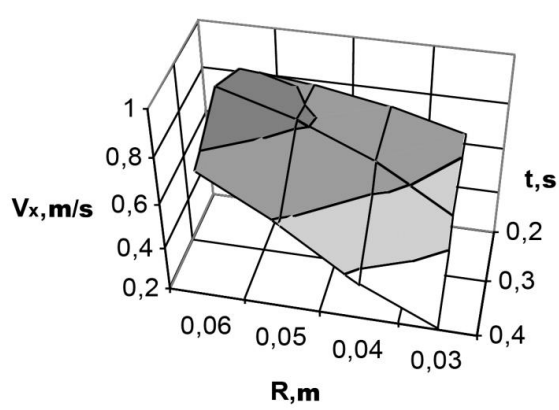

Fig. 9. The surface of the response $V_{x}$ from the radius of the curve and the time of movement

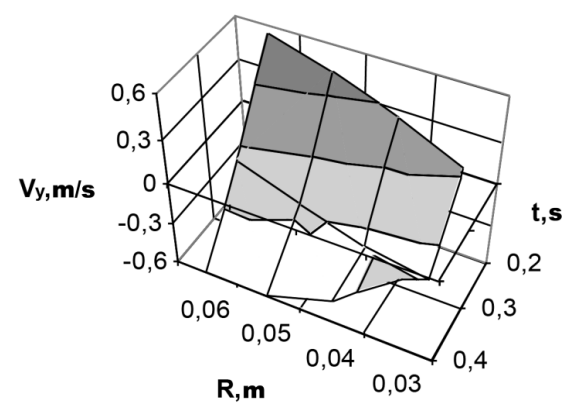

Fig. 10. The surface of the response $V_{y}$ from the radius of the curve and the time of movement 
The speed components were found by differentiating expressions (60) and (61) with respect to time:

$$
\begin{aligned}
& v_{x}=\dot{x}=\frac{d x}{d \varphi} \cdot \dot{\varphi}, \\
& v_{y}=\dot{y}=\frac{d y}{d \varphi} \cdot \dot{\varphi} .
\end{aligned}
$$

Because:

$$
\begin{aligned}
& \frac{d x}{d \varphi}=2 R \sin ^{2} \frac{\varphi}{2}, \\
& \frac{d y}{d \varphi}=2 R \sin \frac{\varphi}{2} \sqrt{1-\sin ^{2} \frac{\varphi}{2}},
\end{aligned}
$$

substituting (82), (85) and (86) in (83) and (84), let's obtain:

$$
\begin{aligned}
& v_{x}=2 \sqrt{g R \frac{a^{2}}{a^{2}+\rho^{2}}} \sin ^{2} \frac{\varphi}{2} \times \\
& \times \frac{\sqrt{\left(\sin \frac{\varphi}{2}-\frac{a}{4 R}\right)^{2}+\frac{W_{0}}{2 m g R}-\frac{a^{2}}{16 R^{2}}}}{\sin \frac{\varphi}{2}-\frac{a}{4 R}} \\
& v_{y}=2 \sqrt{g R \frac{a^{2}}{a^{2}+\rho^{2}}} \sin \frac{\varphi}{2} \sqrt{1-\sin ^{2} \frac{\varphi}{2}} \times \\
& \times \frac{\sqrt{\left(\sin \frac{\varphi}{2}-\frac{a}{4 R}\right)^{2}+\frac{W_{0}}{2 m g R}-\frac{a^{2}}{16 R^{2}}}}{\sin \frac{\varphi}{2}-\frac{a}{4 R}}
\end{aligned}
$$

From the last equations (87), (88) it can be seen that the components of the speed of the ball, which is at point $P$, are expressed through $\sin \varphi / 2$. From relations (63) implies that $\varphi / 2=\pi / 2-\alpha$, that is $\varphi / 2-$ is the angle between the $y$-axis and the tangent to the cycloid (right angle of inclination normal $P K$ to the $x$ axis). Since $0 \leq \varphi \leq \pi$, then $0 \leq \varphi / 2 \leq \pi / 2$ and $\sin \varphi / 2 \geq 0$ :

$$
\begin{aligned}
& v=2 \sqrt{g R \frac{a^{2}}{a^{2}+\rho^{2}}} \sin \frac{\varphi}{2} \times \\
& \times \frac{\sqrt{\left(\sin \frac{\varphi}{2}-\frac{a}{4 R}\right)^{2}+\frac{W_{0}}{2 m g R}-\frac{a^{2}}{16 R^{2}}} .}{\sin \frac{\varphi}{2}-\frac{a}{4 R}} .
\end{aligned}
$$

As a result of solving this problem, the coordinates of the particle, its absolute speed and its components were found, which can be used to substantiate the parameters of the guide elements for seeds in the openers.

\section{2. Experimental comparative studies of openers}

In order to verify the results of theoretical studies, experiments were carried out on the influence of the openers on the agrotechnical indicators of their work. The results are

\begin{tabular}{|c|c|c|c|c|c|c|}
\hline \multirow{2}{*}{ Working bodies } & \multirow{2}{*}{$\begin{array}{l}\text { Speed } \\
(\mathrm{m} / \mathrm{s})\end{array}$} & \multicolumn{5}{|c|}{ Longitudinal uniformity } \\
\hline & & $\bar{x}, \mathrm{~mm}$ & $\sigma, \mathrm{mm}$ & $V, \%$ & $m, \mathrm{~mm}$ & $P, \%$ \\
\hline \multirow{3}{*}{$\begin{array}{l}\text { Seeder+seed } \\
\text { tube }\end{array}$} & 0.78 & 18 & 24.4 & 135.4 & 3.38 & 18.76 \\
\hline & 1.9 & 30 & 31.5 & 105 & 5.48 & 18.3 \\
\hline & 2.65 & 34 & 46.1 & 135.6 & 8.86 & 26.08 \\
\hline \multirow{3}{*}{$\begin{array}{c}\text { Seeder+seed } \\
\text { tube }(1)+\text { test } \\
\text { opener }\end{array}$} & 0.78 & 15 & 17.3 & 115.3 & 2.27 & 4.06 \\
\hline & 1.9 & 18 & 21.78 & 121 & 3.19 & 16.76 \\
\hline & 2.65 & 20 & 18 & 90 & 2.65 & 13.25 \\
\hline \multirow{3}{*}{$\begin{array}{l}\text { Seeder+seed } \\
\text { tube (2) }\end{array}$} & 0.78 & 20 & 16.89 & 84.45 & 2.52 & 12.5 \\
\hline & 1.9 & 26 & 23 & 88.4 & 3.73 & 14.34 \\
\hline & 2.65 & 34 & 27.16 & 80 & 5.04 & 14.85 \\
\hline \multirow{3}{*}{$\begin{array}{c}\text { Seeder }+ \text { seed } \\
\text { tube }(2)+\text { stan- } \\
\text { dard opener } \\
\text { with sharp angle }\end{array}$} & 0.78 & 14 & 17.3 & 123.6 & 2.14 & 3.35 \\
\hline & 1.9 & 23 & 28.72 & 125 & 4.38 & 19.0 \\
\hline & 2.65 & 17 & 14.48 & 85 & 1.97 & 11.6 \\
\hline \multirow{3}{*}{$\begin{array}{l}\text { Seeder+seed } \\
\text { tube (3) }\end{array}$} & 0.78 & 18 & 23.87 & 133 & 3.42 & 19 \\
\hline & 1.9 & 27 & 26.5 & 98.2 & 4.42 & 16.35 \\
\hline & 2.65 & 26 & 31.27 & 120 & 5.28 & 23 \\
\hline \multirow{3}{*}{$\begin{array}{c}\text { Seeder+seed } \\
\text { tube (3)+stan- } \\
\text { dard opener with } \\
\text { obtuse angle }\end{array}$} & 0.78 & 12 & 15.95 & 133 & 1.95 & 16.27 \\
\hline & 1.9 & 19 & 16.27 & 86 & 2.33 & 12.26 \\
\hline & 2.65 & 18 & 19.6 & 109 & 2.67 & 14.8 \\
\hline
\end{tabular}
shown in Tables 1, 2.

Data in Tables 1, 2 allow to state that the experimental opener with a guide and a reflector reduces the coefficient of variation by $20 \ldots 45 \%$. Serial openers: the anchor opener increases this figure by $38 \%$, and the keeled opener reduces

\begin{tabular}{|c|c|c|c|c|c|c|}
\hline \multirow{2}{*}{ Working bodies } & \multirow{2}{*}{$\begin{array}{l}\text { Speed } \\
(\mathrm{m} / \mathrm{s})\end{array}$} & \multicolumn{5}{|c|}{ Longitudinal uniformity } \\
\hline & & $\bar{x}, \mathrm{~mm}$ & $\sigma, \mathrm{mm}$ & $V, \%$ & $m, \mathrm{~mm}$ & $P, \%$ \\
\hline \multirow{3}{*}{$\begin{array}{c}\text { Seeder+seed } \\
\text { tube }\end{array}$} & 0.78 & 39 & 21.02 & 54 & 2.95 & 7.55 \\
\hline & 1.9 & 38 & 17.54 & 46.5 & 3.03 & 7.96 \\
\hline & 2.65 & 36 & 20.1 & 56.7 & 3.86 & 10.7 \\
\hline \multirow{3}{*}{$\begin{array}{c}\text { Seeder+seed } \\
\text { tube }(1)+\text { test } \\
\text { opener }\end{array}$} & 0.78 & 19 & 7.04 & 37 & 0.94 & 1.68 \\
\hline & 1.9 & 22 & 9.08 & 41.3 & 1.11 & 5.05 \\
\hline & 2.65 & 29 & 15.33 & 52.8 & 2.25 & 7.78 \\
\hline \multirow{3}{*}{$\begin{array}{l}\text { Seeder+seed } \\
\text { tube (2) }\end{array}$} & 0.78 & 46 & 19.63 & 42.85 & 3.03 & 6.6 \\
\hline & 1.9 & 66 & 19.75 & 30 & 3.2 & 4.86 \\
\hline & 2.65 & 44 & 20.7 & 47 & 3.12 & 7.08 \\
\hline \multirow{3}{*}{$\begin{array}{c}\text { Seeder+seed } \\
\text { tube }(2)+\text { stan- } \\
\text { dard opener } \\
\text { with sharp angle }\end{array}$} & 0.78 & 48 & 14.69 & 34 & 2.03 & 6.62 \\
\hline & 2.65 & 72 & 21.9 & 29.4 & 3.0 & 7.13 \\
\hline & 1.9 & 75 & 27.34 & 36.5 & 2.98 & 7.84 \\
\hline \multirow{3}{*}{$\begin{array}{l}\text { Seeder+seed } \\
\text { tube (3) }\end{array}$} & 0.78 & 35 & 16.4 & 47 & 2.32 & 6.62 \\
\hline & 1.9 & 38 & 18.38 & 48.4 & 2.98 & 7.84 \\
\hline & 2.65 & 42 & 16.69 & 39.7 & 3.0 & 7.13 \\
\hline \multirow{3}{*}{$\begin{array}{c}\text { Seeder+seed } \\
\text { tube }(3)+\text { stan- } \\
\text { dard opener with } \\
\text { obtuse angle }\end{array}$} & 0.78 & 64 & 27.1 & 42.3 & 3.73 & 5.7 \\
\hline & 1.9 & 73 & 30.8 & 41.2 & 4.24 & 5.8 \\
\hline & 2.65 & 89 & 26.82 & 30.2 & 3.3 & 3.71 \\
\hline
\end{tabular}
the coefficient of variation by $12.2 \%$.

Table 1

The influence of the openers on the longitudinal uniformity of sowing wheat seeds

Table 2

Influence of openers of various designs and their speed of movement on the lateral uniformity of sowing wheat seeds 
The presence of a seed guide and reflector in the opener

affected the improvement of the seeding uniformity.

Keel-shaped openers were investigated in the field.

Number 1 is the control serial keeled opener.

Opener No. 2 is an experimental keeled opener with a curved seed guide.

Opener No. 3 is an experimental opener equipped with a straight-line seed guide.

Opener No. 4 is an experimental working body equipped with a curvilinear guide and a seed reflector.

In the field, the openers were assessed by the uniformity of seed distribution along the row and in depth. The research results are presented in Tables 3,4 .

Data in Tables 3, 4 showed the best results in the experimental opener with a guide and a reflector (No. 4).

With an arithmetic mean interval along the row of 18.5...23.5 $\mathrm{mm}$ and a coefficient of variation of $88 . . .98 \%$.

The worst results along the row were shown by the control opener (No. 1) with the result $\bar{x}=11 \ldots 21 \mathrm{~mm}$ and $V=91 \ldots 110 \%$.

The second and third openers had results between the first and fourth.

In terms of the distribution of seeds by depth, the best results were shown by opener No. 4, which more deeply and evenly placed seeds $\bar{x}=42 \ldots 37 \mathrm{~mm}$ and $V=24 \ldots 27 \%$.

Table 3

Influence of the parameters of the front openers and the speed of their movement on the distribution of seeds along the row

\begin{tabular}{|c|c|c|c|c|c|c|}
\hline \multirow{3}{*}{ Openers } & \multirow{2}{*}{$\begin{array}{c}\text { Speed } \\
\mathrm{m} / \mathrm{s}\end{array}$} & \multicolumn{5}{|c|}{ Indicators } \\
\cline { 3 - 7 } & & $x, \mathrm{~mm}$ & $\sigma, \mathrm{mm}$ & $V, \%$ & $m, \mathrm{~mm}$ & $P, \%$ \\
\hline \multirow{4}{*}{ No. 1} & 0.79 & 11 & 10.01 & 91 & 0.5 & 4.55 \\
\cline { 2 - 7 } & 1.85 & 16 & 16.16 & 101 & 0.67 & 4.2 \\
\cline { 2 - 7 } & 2.66 & 21 & 23.1 & 110 & 0.96 & 4.5 \\
\hline \multirow{4}{*}{ No. 2} & 0.79 & 17 & 15.64 & 92 & 0.78 & 4.6 \\
\cline { 2 - 7 } & 1.85 & 20.5 & 20.29 & 99 & 1.01 & 4.9 \\
\cline { 2 - 7 } & 2.66 & 22 & 23.76 & 108 & 0.99 & 4.5 \\
\hline \multirow{4}{*}{ No.3 } & 0.79 & 14 & 12.18 & 87 & 0.5 & 3.6 \\
\cline { 2 - 7 } & 1.85 & 18 & 17.1 & 95 & 0.85 & 4.75 \\
\cline { 2 - 7 } & 2.66 & 21.5 & 22.14 & 103 & 0.92 & 4.2 \\
\hline \multirow{4}{*}{ No.4 } & 0.79 & 18.5 & 16.28 & 88 & 0.81 & 4.4 \\
\cline { 2 - 7 } & 1.85 & 21 & 19.74 & 94 & 0.98 & 4.7 \\
\cline { 2 - 7 } & 2.66 & 23.5 & 23.03 & 98 & 1.25 & 4.9 \\
\hline
\end{tabular}

Influence of the parameters of the front openers and the speed of their movement on the distribution of seeds along the depth

\begin{tabular}{|c|c|c|c|c|c|c|}
\hline \multirow{3}{*}{ Openers } & \multirow{2}{*}{$\begin{array}{c}\text { Speed } \\
\mathrm{m} / \mathrm{s}\end{array}$} & \multicolumn{5}{|c|}{ Indicators } \\
\cline { 2 - 7 } & & $x, \mathrm{~mm}$ & $\sigma, \mathrm{mm}$ & $V, \%$ & $m, \mathrm{~mm}$ & $P, \%$ \\
\hline \multirow{4}{*}{ No. 1} & 0.79 & 36.5 & 10.58 & 29 & 1.5 & 4.1 \\
\cline { 2 - 7 } & 1.85 & 30 & 10.8 & 36 & 1.3 & 4.3 \\
\cline { 2 - 7 } & 2.66 & 23 & 10.12 & 44 & 1.1 & 4.78 \\
\hline \multirow{4}{*}{ No. 2} & 0.79 & 35.5 & 11.0 & 31 & 1.1 & 3.09 \\
\cline { 2 - 7 } & 1.85 & 30 & 11.4 & 38 & 1.09 & 3.6 \\
\cline { 2 - 7 } & 2.66 & 24 & 10.08 & 42 & 1.0 & 4.16 \\
\hline \multirow{4}{*}{ No.3 } & 0.79 & 43 & 11.18 & 26 & 1.1 & 2.55 \\
\cline { 2 - 7 } & 1.85 & 39 & 10.92 & 28 & 1.09 & 2.79 \\
\cline { 2 - 7 } & 2.66 & 35 & 11.55 & 33 & 1.13 & 3.22 \\
\hline \multirow{4}{*}{ No.4 } & 0.79 & 42 & 10.08 & 24 & 1.0 & 2.38 \\
\cline { 2 - 7 } & 1.85 & 40 & 10.0 & 25 & 1.0 & 2.5 \\
\cline { 2 - 7 } & 2.66 & 37 & 9.9 & 27 & 0.99 & 2.67 \\
\hline
\end{tabular}

The results clearly show that the experimental opener No. 4 and opener No. 3 place seeds in depth in a one-centimeter layer, which corresponds to modern agricultural requirements.

This is due to the presence of guides with reasonable parameters in the openers.

In order to substantiate the presence and quantity of guiding elements for seeds in the opener in laboratory conditions, such openers were investigated (Tables 5, 6).

Experimental front openers with four guides, three, two and control serial double-disc, keeled and opener according to [22].

Data in Tables 5, 6 showed the best results on models with four and three guide elements in the front openers.

It is recommended to install an improved seed guide in the double disc opener.

For this purpose, laboratory studies of models of working organs with such guides were carried out.

Under No. 1, a serial double-disc opener was used (control).

Under No. 2, an experimental double-disc opener with an improved curvilinear guide was used.

In experimental double-disc openers No. 3 and No. 4, curvilinear guides were used in each subsequent guide $2 \mathrm{~cm}$ longer than in the previous one.

The seeding results are presented in Table 7 .

Table 5

Uniform distribution of seeds along the row in laboratory conditions

\begin{tabular}{|c|c|c|c|c|c|c|c|c|c|c|c|c|}
\hline \multirow{3}{*}{ Openers } & \multicolumn{12}{|c|}{ Opener speed, m/s } \\
\hline & \multicolumn{3}{|c|}{1.0} & \multicolumn{3}{|c|}{1.3} & \multicolumn{3}{|c|}{2.1} & \multicolumn{3}{|c|}{2.5} \\
\hline & $\bar{x}, \mathrm{~mm}$ & $\sigma, \mathrm{mm}$ & $V, \%$ & $\bar{x}, \mathrm{~mm}$ & $\sigma, \mathrm{mm}$ & $V, \%$ & $\bar{x}, \mathrm{~mm}$ & $\sigma, \mathrm{mm}$ & $V, \%$ & $\bar{x}, \mathrm{~mm}$ & $\sigma, \mathrm{mm}$ & $V, \%$ \\
\hline With 4 guides & 15.8 & 17.0 & 107.6 & 17.2 & 17.0 & 98.0 & 20.0 & 20.6 & 104.0 & 24.6 & 25.0 & 101.0 \\
\hline With 3 guides & 11.0 & 13.6 & 123.0 & 16.01 & 17.0 & 106.0 & 29.5 & 29.0 & 98.2 & 24.0 & 27.9 & 116.0 \\
\hline With 4 guides & 10.0 & 12.9 & 129.0 & 17.0 & 17.6 & 97.8 & 18.0 & 22.2 & 127.0 & 26.0 & 35.5 & 128.0 \\
\hline Experimental [22] & 18.7 & 20.7 & 111.0 & 14.0 & 16.4 & 115.0 & 24.0 & 30.8 & 127.0 & 39.0 & 34.2 & 87.5 \\
\hline Double-disc & 26.4 & 28.6 & 108.0 & 16.0 & 23.4 & 146.0 & 26.0 & 35.4 & 136.0 & 26.0 & 32.5 & 125.0 \\
\hline Keeled & 17.5 & 18.0 & 102.0 & 21.4 & 23.97 & 112.0 & 47.0 & 35.0 & 123.0 & 21.0 & 23.5 & 112.0 \\
\hline
\end{tabular}


Table 6

Uniform distribution of seeds across the row in laboratory condition

\begin{tabular}{|c|c|c|c|c|c|c|c|c|c|c|c|c|}
\hline \multirow{3}{*}{ Openers } & \multicolumn{12}{|c|}{ Opener speed, m/s } \\
\hline & \multicolumn{3}{|c|}{1.0} & \multicolumn{3}{|c|}{1.3} & \multicolumn{3}{|c|}{2.1} & \multicolumn{3}{|c|}{2.5} \\
\hline & $\bar{x}, \mathrm{~mm}$ & $\sigma, \mathrm{mm}$ & $V, \%$ & $\bar{x}, \mathrm{~mm}$ & $\sigma, \mathrm{m}$ & $V, \%$ & $\bar{x}, \mathrm{~mm}$ & $\sigma, \mathrm{mm}$ & $V, \%$ & $\bar{x}, \mathrm{~mm}$ & $\sigma, \mathrm{mm}$ & $V, \%$ \\
\hline With 4 guides & 47.2 & 38.0 & 48.6 & 74.0 & 24.8 & 35.5 & 54.0 & 29.3 & 54.4 & 45.0 & 29.2 & 56.50 \\
\hline With 3 guides & 44.0 & 18.9 & 43.0 & 40.0 & 15.4 & 39.0 & 38.2 & 20.0 & 52.4 & 48.0 & 16.7 & 34.8 \\
\hline With 4 guides & 39.0 & 14.6 & 37.4 & 42.0 & 14.5 & 34.6 & 70.0 & 28.6 & 41.0 & 82.5 & 51.5 & 58.0 \\
\hline Experimental [22] & 18.7 & 58.0 & 61.0 & 47.0 & 18.7 & 39.8 & 57.0 & 31.5 & 55.4 & 65.0 & 30.8 & 47.5 \\
\hline Double-disc & 47.0 & 28.8 & 61.5 & 74.0 & 28.7 & 36.3 & 95.0 & 35.2 & 35.0 & 65.0 & 45.0 & 70.5 \\
\hline Keeled & 64.0 & 31.5 & 49.3 & 41.0 & 22.8 & 55.5 & 39.0 & 23.0 & 58.3 & 47.0 & 25.5 & 58.6 \\
\hline
\end{tabular}

Table 7

Table 8

Uniform distribution of seeds along the row

\begin{tabular}{|c|c|c|c|c|c|}
\hline \multirow{2}{*}{ Working bodies } & \multicolumn{5}{|c|}{ Indicators } \\
\cline { 2 - 6 } & $\bar{x}, \mathrm{~mm}$ & $\sigma, \mathrm{mm}$ & $\theta, \%$ & $m, \mathrm{~mm}$ & $P, \%$ \\
\hline No. 1 & 17 & 18.57 & 109.0 & 0.74 & 4.3 \\
\hline No. 2 & 16 & 17.13 & 107.0 & 0.68 & 4.25 \\
\hline No. 3 & 15 & 16.01 & 106.7 & 0.64 & 4.26 \\
\hline No. 4 & 15 & 16.00 & 106.0 & 0.67 & 4.46 \\
\hline
\end{tabular}

Data in Table 7 show that the arithmetic mean interval between seeds for all openers is approximately the same $15 \ldots 17 \mathrm{~mm}$, and the coefficient of variation is in the range from 106 to $109 \%$.

Based on these studies, a curved, improved guide can be recommended for the double disc opener. The bottom edge of the guide should protrude $2 \mathrm{~cm}$ in front of the vertical diameter of the discs and are located at a distance of $9 \mathrm{~cm}$ from the reference plane.

Model No. 4 of the table corresponds to such setting parameters of the seed guide. 7 in which the arithmetic mean spacing along the row is $15 \mathrm{~mm}$ and the coefficient of variation is $106 \%$, the smallest of the studied models.

The results of studies to substantiate the presence, quantity and parameters of the seed guide elements make it possible to recommend the use of seed guides in the openers. This improves the uniformity of seed distribution over the area.

The number of guides in the openers must be at least $3 . . .4$, and the lower one must ensure the movement of the seeds backward along the movement of the seeder to equalize their speeds.

It is recommended to install one curvilinear guide in a double-disc opener so that its lower edge is $2 \mathrm{~cm}$ in front of the vertical diameter of the discs and is $9 \mathrm{~cm}$ from the reference plane.

Investigations of experimental and serial openers were carried out in the field (Tables 8, 9).

The experiment involved an experimental hand opener with a seed guide and reflector, serial keeled and anchor openers.

The results of the experiment allow to state that the serial openers showed worse uniformity in comparison with the experimental working body. This is due to the fact that in the serial anchor opener the shape, design and setting parameters of the reflective plate are not chosen rational, since there is no scientific justification for them, and in the keeled opener there is no guide element for seeds.
Influence of the design features of the openers on the uniformity of seed distribution along the row

\begin{tabular}{|c|c|c|c|c|c|c|}
\hline \multirow{2}{*}{ Openers } & $\begin{array}{c}\text { Seeder } \\
\text { speed, } \\
\mathrm{m} / \mathrm{s}\end{array}$ & \multicolumn{5}{|c|}{ Uniformity indicators } \\
\cline { 2 - 7 } & $\bar{x}, \mathrm{~mm}$ & $\sigma, \mathrm{mm}$ & $V, \%$ & $m, \mathrm{~mm}$ & $P, \%$ \\
\hline $\begin{array}{c}\text { Experimental } \\
\text { with guide and }\end{array}$ & 0.78 & 26 & 22.4 & 86.2 & 3.6 & 13.9 \\
\cline { 2 - 7 } $\begin{array}{c}\text { reflector seed } \\
\text { reflector }\end{array}$ & 1.9 & 23 & 21.6 & 93.8 & 3.2 & 14.4 \\
\cline { 2 - 7 } & 2.65 & 24 & 24.1 & 100 & 3.6 & 14.7 \\
\hline \multirow{4}{*}{ Serial keeled } & 0.78 & 24 & 22.7 & 94.5 & 5.9 & 24.4 \\
\cline { 2 - 7 } & 1.9 & 25 & 24.6 & 95.0 & 4.7 & 18.2 \\
\cline { 2 - 7 } & 2.65 & 24 & 25.6 & 106.5 & 4.0 & 16.8 \\
\hline \multirow{4}{*}{ Serial anchor } & 0.78 & 22 & 19.4 & 88.5 & 3.0 & 13.4 \\
\cline { 2 - 7 } & 1.9 & 26 & 29.7 & 108.0 & 5.6 & 20.6 \\
\cline { 2 - 7 } & 2.65 & 31 & 48 & 155 & 9.4 & 33.0 \\
\hline
\end{tabular}

Table 9

The influence of the design features of the openers on the uniformity of the distribution of seeds along the depth

\begin{tabular}{|c|c|c|c|c|c|c|}
\hline \multirow{2}{*}{ Openers } & $\begin{array}{c}\text { Seeder } \\
\text { speed, } \\
\mathrm{m} / \mathrm{s}\end{array}$ & \multicolumn{5}{|c|}{ Uniformity indicators } \\
\cline { 2 - 7 } & $\overline{\mathrm{mm}}$ & $\sigma, \mathrm{mm}$ & $V, \%$ & $m, \mathrm{~mm}$ & $P, \%$ \\
\hline $\begin{array}{c}\text { Experimental } \\
\text { with guide and } \\
\text { reflector seed } \\
\text { reflector }\end{array}$ & 0.78 & 62.0 & 3.0 & 4.9 & 0.5 & 0.9 \\
\cline { 2 - 7 } & 1.9 & 48.4 & 3.9 & 8.0 & 0.6 & 1.3 \\
\hline \multirow{4}{*}{ Serial keeled } & 2.65 & 45 & 3.9 & 8.6 & 0.7 & 1.1 \\
\cline { 2 - 7 } & 0.78 & 46.0 & 7.0 & 20.3 & 1.2 & 2.6 \\
\cline { 2 - 7 } & 2.65 & 48.0 & 8.8 & 18.4 & 1.4 & 3.0 \\
\hline \multirow{4}{*}{ Serial anchor } & 0.78 & 93.0 & 11.5 & 12.5 & 1.09 & 2.0 \\
\cline { 2 - 7 } & 1.9 & 73.5 & 10.5 & 14.3 & 1.5 & 2.0 \\
\cline { 2 - 7 } & 2.65 & 54 & 9.2 & 17.1 & 1.0 & 1.9 \\
\hline
\end{tabular}

This assessment is confirmed by the data in Table 8 . The arithmetic mean interval and the coefficient of variation for the experimental opener are $26 . .24 \mathrm{~mm}$ and $86.2 \ldots 100 \%$, respectively; for the serial keeled $24 \ldots .25 \mathrm{~mm}$ and $94.5 \ldots 106.5 \%$; for the serial anchor opener $22 \ldots 31 \mathrm{~mm}$ and $88.5 \ldots 155.0 \%$.

The arithmetic mean interval and the coefficient of variation in depth, respectively (Table 9): for the experimental opener $62.0 \ldots 45.0 \mathrm{~mm}$ and $4.9 \ldots 8.6 \%$; in the serial keeled $46.0 \ldots 26.0 \mathrm{~m}$ and $20.3 \ldots 27.8 \%$; for the serial anchor 93.0...54.0 $\mathrm{mm}$ and $12.5 \ldots 17.1 \%$. 
The conclusion suggests itself that it is necessary to install seed guides justified in all parameters in serial openers, which improve the uniformity of seed distribution.

The presented materials confirm the correctness of the direction of research and their prospects.

\section{Discussion of theoretical and experimental studies for increasing sowing efficiency}

Based on the analysis of the functioning of the openers and the development of their research, it was established that the movement of seeds in the openers is not regulated or controlled. And as a consequence, the quality of sowing and the yield of agricultural crops are reduced. It was also found that the improvement of the uniformity of seed distribution [3-6] in the soil is realized by various methods. One of the relatively new and promising ones is the grain flow control by the seed guides in the openers. This creates favorable conditions for the flight of seeds in the opener and when leaving it back, which equalizes, in modulus, the speed of the seeds and the unit. A number of problems have been solved to substantiate the parameters of the movement of seeds on various surfaces.

The presence and parameters of the guiding elements of their interaction with the seeds were theoretically substantiated, which gave the development of the process of controlling the grain flow in the openers and at the exit from them. This allows to purposefully form the grain flow, direct it in the right direction at a certain speed to equalize, in modulus, the speeds of seeds and aggregate, improve the uniformity of seed distribution in the soil, which increases the yield.

In this case, the coefficient of variation of the longitudinal uniformity of seed distribution in the row decreases by $20 \ldots 45 \%$, and the transverse one - by $4 \ldots 17 \%$.

The experiment to determine the number of guides in the sub-openers showed (Table 5) that the experienced openers have the best results. The best among them was the opener with four guides, which had a coefficient of variation of 107.6...98\%.

In serial openers, this indicator was: for a two-disc opener $146 \ldots 108 \%$, and for a keeled opener $123 . . .102 \%$.

An experiment was carried out to substantiate the guide in a two-disc opener (Table 7).

Based on these studies, a curvilinear improved guide can be recommended for the double disc opener. The bottom edge of the guide protrudes $2 \mathrm{~cm}$ in front of the vertical diameter of the discs and lags behind the reference plane at a distance of $9 \mathrm{~cm}$.

The experimental results confirm theoretical studies that the presence of a seed guide and reflector with scientifically grounded parameters reduce the average coefficient of variation of longitudinal uniformity by $20 . . .45 \%$, and transverse uniformity by $4 . . .17 \%$.

It has been established that two ways can be used: the formation of the grain flow and its control in the openers, as well as the elimination of the soil sloping soil surface, on which the seeds are unevenly distributed in depth.

The advantages of the proposed solutions are explained by the following: the method uses a causal relationship between the parameters of the openers and the operations of the technological process and the operational method for assessing the quality of individual operations. These techniques make it possible to evaluate each operation without waiting for the end of the technological process. Thus, the corrected (improved) operation is the starting material for subsequent operations, the technological process is improved and its efficiency is increased.
Guides with certain characteristics can be used for sowing seeds with appropriate physical and mechanical properties to obtain high-quality sowing with a subsequent increase in yield.

The proposed solutions make it possible to close the problematic part in this way: the characteristics of the movement of seeds on such surfaces are determined: an inclined plane, an arc of a circle, an arc of a cycloid.

The results obtained can be used in seed guides with appropriate physical and mechanical properties to improve the sowing quality and increase the yield.

The following limitations are inherent: when justifying the number of guides (Table 5), the model with four guides has the best results. But with an increase in their number, the permeability of the seeds will be difficult and the opener will be clogged. Therefore, let's limit ourselves to four guiding elements.

Also, a new and promising method of formation and management of seeds in openers and when leaving them was applied.

The combination of seed flight control and a new method of soil shedding [12] eliminates the sloped sub-opener surface, which significantly improves the uniformity of seed distribution in the soil (Tables 1,2). An experimental opener with a guide and a reflector reduces the coefficient of variation of the longitudinal uniformity by $20 \ldots 45 \%$. Serial openers: keeled openers reduce this figure by $0 \ldots 12.2 \%$, and anchor openers increase this factor by $38 \%$.

An experiment to justify the guides in the openers (Table 5) revealed the best indicators of the uniformity of seed distribution along the row for models with four guiding elements:= $=15.8 \ldots 24.6 \mathrm{~mm}$ and the coefficient of variation $-107.6 \ldots 98 \%$.

An experiment to substantiate the parameters of the guide in a two-disc opener (Table 7) allows to conclude that the best opener was No. 4 with indicators along the row $=15 \mathrm{~mm}$ and a coefficient of variation of $106 \%$.

Comparative studies of the openers in terms of the uniformity of seed distribution along the row and in depth also showed the advantages of experimental openers with guides and a reflector (Tables 8, 9).

The arithmetic mean interval and the coefficient of variation along the row were recorded: for the experimental head $\bar{x}=20 \ldots 24 \mathrm{~mm}$ and $V=86.2 \ldots 100 \%$; for serial ones: keeled $\bar{x}=24 \ldots 25 \mathrm{~mm}$ and $V=94.5 \ldots 106.5 \%$; for anchor $\bar{x}=21 \ldots 31 \mathrm{~mm}$ and $V=88.5 \ldots 155.0 \%$.

Uniformity in depth: for the experimental one $\bar{x}=62 \ldots 45 \mathrm{~mm}, \quad V=4.9 \ldots 8.6 \%$; for serial ones: keeled $\bar{x}=46 \ldots 26 \mathrm{~mm}, V=20.3 \ldots 27.8 \%$; for anchor $\bar{x}=93.0 \ldots 54.0 \mathrm{~mm}$, $V=12.5 \ldots 17.1 \%$.

Field experiments (Tables 3, 4) showed that the experienced openers have the best indicators of seed distribution along the row and in depth.

Opener No. 4 along the row showed: the arithmetic mean interval $18.5 \ldots 23.5 \mathrm{~mm}$ and $V=88 \ldots 98 \%$, and the control keeled, respectively $=36.5 \ldots 23 \mathrm{~mm}$ and $V=29 \ldots 44 \%$.

The following were shown in depth: for an experienced opener with a guide and a reflector $\bar{x}=42 \ldots 47 \mathrm{~mm}$, $V=24 \ldots 27 \%$; at the control opener $\bar{x}=36.5 \ldots 23.0 \mathrm{~mm}$, and $V=29 . .44 \%$.

It is easy to see that experimental opener No. 4 with a guide and a reflector places the seeds at a depth in a one-centimeter layer, which corresponds to agricultural requirements. And this is due to the presence of a seed guide and reflector and the elimination of the sloped surface.

The number of guides in the central sub-openers should be at least 3-4, and the lower one should ensure the move- 
ment of the seeds backward along the movement of the seeder to equalize their speeds.

The advantages of the proposed solutions are explained by the use of a new and promising method of forming the grain flow and controlling it in the openers in the desired direction. This is achieved:

- the use of guiding elements with certain characteristics for seeds with appropriate physical and mechanical properties with varying modes of operation of seeders;

- the elimination of the sib-opener inclined surface by the interaction of seed guides and a new process of soil shattering during the movement of the opener [12].

The research used a promising method of causal relationship between the parameters of the openers with the operations of the technological process and a certain method for assessing the quality of individual operations.

The following limitations are inherent.

Disc and anchor openers with an acute angle of entry into the soil are dangerous on well-cut or light soils, since they provide such a deep embedding of seeds that partial death of seedlings is possible.

\section{Conclusions}

1. Analytical expressions are obtained to determine the various characteristics of the motion of particles on diffe- rent surfaces. When modeling the process of particle motion along an inclined plane without friction and sliding, the following are determined: particle acceleration, coordinates, speed components. When moving along an arc of a circle, the following are determined: the coordinates of the particle, the speed of the particle and its components. When moving along an arc, the cycloid is determined: coordinates, speed and its components, acceleration and its components.

2. Studies of the effect of openers on the longitudinal uniformity of sowing wheat seeds showed the following results. An experienced opener reduces the coefficient of variation by $20 \ldots 45 \%$, serial: the keeled opener reduces this indicator by $0 \ldots 12.2 \%$, the anchor opener increases this coefficient by $38 \%$. Field studies of the distribution of seeds along the row showed that the coefficient of variation has the following values: experimental opener $86.2 \ldots 100 \%$, serial: keeled 94.5...106.5\%, anchor - 88.5...155\%...The depth indicators were as follows: the arithmetic mean interval and the coefficient of variation, respectively: for the experimental opener $62 \ldots 45 \mathrm{~mm}$, and $4.9 \ldots 8.6 \%$; in serial: keeled $-46 \ldots 26 \mathrm{~mm}$ and 20.3...27.8\%, anchor - 93...54 mm and 12.5...17.1\%. The experimental opener places the seeds more evenly in depth and showed the best coefficient of variation. This is due to the presence and parameters of the seed guiding elements, which not only regulates the flow of seeds, but also eliminates the inclined sub-opener soil surface together with improved furrow formation.

\section{References}

1. Parhomenko, Y., Kondratec, V., Parhomenko, M. (2011). The definition of mathematical model of the process of formation of a grain stream on an output of the bobbin sowing device. Konstruiuvannia, vyrobnytstvo ta ekspluatatsiya silskohospodarskykh mashyn, 41 (2), 62-68. Available at: http://dspace.kntu.kr.ua/jspui/bitstream/123456789/2075/1/12.pdf

2. Liu, D., Dong, H., Zhang, B., You, J., Yu, X. (2021). Design of Seed Rope Guiding Opener Based on DEM. Journal of Physics: Conference Series, 1744 (2), 022127. doi: https://doi.org/10.1088/1742-6596/1744/2/022127

3. Lopareva, S. G., Mekshun, Y. N., Loparev, D. V. (2021). Field Tests of Colters with Two-Plane Grass Seed Spreader. IOP Conference Series: Earth and Environmental Science, 666 (2), 022070. doi: https://doi.org/10.1088/1755-1315/666/2/022070

4. Priporov, E. V., Levchenko, D. S. (2015). Analysis of openers of seeders in resource saving technologies of grain planting. Nauchniy zhurnal KubGAU, 109 (05). Available at: http://ej.kubagro.ru/2015/05/pdf/23.pdf

5. Kuvaitsev, V. N., Larushin, N. P., Karasyov, I. Ye. (2016). Construction of combined opener for planting small-seeded oilseed crops. Niva Povolzh'ya, 1 (38), 67-73. Available at: https://cyberleninka.ru/article/n/konstruktsiya-kombinirovannogososhnika-dlya-poseva-melkosemennyh-maslichnyh-kultur/viewer

6. Makarenko, A. N. (2014). Modelirovanie protsessa dvizheniya pochvy po poverhnosti rabochih organov pochvoobrabatyvayuschih mashin s izmenennoy geometriey na primere kul'tivatornoy lapy. Problemy mekhanizatsii i elektrifikatsii sel'skogo hozyaystva: Materialy Vserossiyskoy nauchno-prakticheskoy konferentsii. Krasnodar: Kubanskiy GAU, 149-153. Available at: https://kubsau. ru/upload/iblock/654/6545dfa0ca4d4b3b7870153b96ee73c1.pdf

7. Salo, V., Haidenko, O. (2016). Osnovni typy soshnykiv dlia priamoi sivby zernovykh kultur. Ahrobiznes sohodni. Available at: http:// agro-business.com.ua/agro/mekhanizatsiia-apk/item/1242-osnovni-typy-soshnykiv-dlia-priamoi-sivby-zernovykh-kultur.html

8. Savinych, P. A., Kurbanov, R., Kuboń, M., Kamionka, J. (2015). Stability of semi-mounted sod seeder motion. Agricultural Engineering, 3 (155), 101-108. Available at: https://ir.ptir.org/artykuly/en/155/IR(155)_3672_en.pdf

9. Adamchuk, V., Bulgakov, V., Gorobey, V. (2016). Theory of two-disc anchor opener of grain drill. Scientific proceedings i international scientific conference «Conserving Soils and Water» 2016, 24, 71-73. Available at: http://conserving-soils.eu/sbornik/2016/18. THEORY\%20OF\%20TWO-DISC\%20ANCHOR\%20OPENER\%20OF\%20GRAIN\%20DRILL.pdf

10. Kornienko, S., Pashenko, V., Melnik, V., Kharchenko, S., Khramov, N. (2016). Developing the method of constructing mathematical models of soil condition under the action of a wedge. Eastern-European Journal of Enterprise Technologies, 5 (7 (83)), 34-43. doi: https://doi.org/10.15587/1729-4061.2016.79912

11. Zubrilina, E., Vysochkina, L., Danilov, M., Maliyev, V. (2017). Design modification of seed distributor of pneumatic seeder for corn sowing. Engineering for rural development, 772-778. doi: https://doi.org/10.22616/erdev2017.16.n158 
12. Soloviev, S. V., Abrosimov, A. G., Dyachkov, S. V., Bakharev, A. A., Kartechina, N. V., Zavrazhnov, A. A. (2021). Theoretical substantiation of the design of the opener of the beet seeder. IOP Conference Series: Earth and Environmental Science, 677 (4), 042114. doi: https://doi.org/10.1088/1755-1315/677/4/042114

13. Zhao, S., Tan, H., Wang, J., Yang, C., Yang, Y. (2018). Design and experiment of multifunctional integrated seeding opener. Transactions of the Chinese Society of Agricultural Engineering, 34 (11), 58-67. doi: https://doi.org/10.11975/j.issn.1002-6819.2018.11.008

14. Gao, Q., Chen, Y., Zhou, H., Al-Amin Sadek, M. (2015). Simulation of a seed opener using the discrete element method (DEM). Agricultural Engineering International: The CIGR e-journal, 17 (3), 72-82.

15. Hasimu, A., Chen, Y. (2014). Soil disturbance and draft force of selected seed openers. Soil and Tillage Research, 140, 48-54. doi: https://doi.org/10.1016/j.still.2014.02.011

16. Dmytro, A., Mykola, S., Volodymyr, O., Viktor, D., Vitaliy, M. (2021). Grounding of Design and Technology Parameters of Combined Coulter Furrow Opener of Precision Seed Drill. Alinteri Journal of Agriculture Sciences, 36 (2), 53-61. doi: https://doi.org/ 10.47059/alinteri/v36i2/ajas21114

17. Mazorenko, D. I., Boichenko, S. F., Bakum, M. V., Nikitin, S. P., Nikitina, O. S. (2002). Pat. No. 55681 UA. Method of sowing agricultural crops and a ploughshare for carrying out thereof. No. 2002043366; declareted: 23.04.2002; published: 15.04.2003, Bul. No. 4. Available at: https://uapatents.com/6-55681-sposib-posivu-silskogospodarskikh-kultur-ta-soshnik-dlya-jjogo-zdijjsnennya.html

18. Aikins, K. A., Jensen, T. A., Antille, D. L., Barr, J. B., Ucgul, M., Desbiolles, J. M. A. (2021). Evaluation of bentleg and straight narrow point openers in cohesive soil. Soil and Tillage Research, 211, 105004. doi: https://doi.org/10.1016/j.still.2021.105004

19. Morozov, I. V. (1974). Issledovanie soshnikov v laboratornyh usloviyah. Sel'skohozyaystvennye mashiny: Sb. nauchn. tr. MIISP. Moscow, XI (1 (II)), 43-47.

20. Morozov, I. V., Soloshenko, A. V. (1984). Ob ustoychivosti dvizheniya soshnikov po glubine. Povyshenie effektivnosti s.h. mashin i orudiy dlya rastenievodstva. Mezhvuzovskiy sb. nauchn. tr. MIISP. Moscow, 94-96.

21. Trofimchenko, Yu. I., Morozov, I. V., Kirichenko, V. A., Slobodyuk, A. V. (1986). O dvizhenii semyan ili tukov v mezhdiskovom prostranstve soshnikov. Sovershenstvovanie tekhnologicheskih protsessov i rabochih organov sel'skohozyaystvennyh mashin: Sb. nauchn. tr. MIISP. Moscow, 28-34.

22. Morozov, I. V., Vlasenko, V. H., Doan Dyk Vin (1988). Perspektyvni naukovo obgruntovani udoskonalennia zarobliuiuchykh robochykh orhaniv zernovykh sivalok. Naukovyi visnyk Natsionalnoho ahrarnoho universytetu, 9, 85-87.

23. Zaika, P. M. (1922). Izbrannye zadachi zemledel'cheskoy mekhaniki. Kyiv: Izdatel'stvo USKHA, 507.

24. Nanka, A., Morozov, I., Morozov, V., Krekot, M., Poliakov, A., Kiralhazi, I. et. al. (2019). Improving the efficiency of a sowing technology based on the improved structural parameters for colters. Eastern-European Journal of Enterprise Technologies, 4 (1 (100)), 33-45. doi: https://doi.org/10.15587/1729-4061.2019.174445 